\title{
Environmental Pollution: The Essence and Solution
}

\author{
Li Zhou \\ School of Chemical Engineering and Technology, Tianjin University, Tianjin, China \\ Email: zhouli@tju.edu.cn
}

Received 8 April 2014; revised 8 May 2014; accepted 15 May 2014

Copyright (C) 2014 by author and Scientific Research Publishing Inc.

This work is licensed under the Creative Commons Attribution International License (CC BY).

http://creativecommons.org/licenses/by/4.0/

(c) (i) Open Access

\begin{abstract}
Environmental pollution is the result of human activities, which causes carbon accumulation on the earth. The accumulated carbon resides not only in $\mathrm{CO}_{2}$, but also in urban garbage, aquatic weeds, agricultural refuses and other wastes. The forced carbon circulation (FCC) strategy aims to bringing the accumulated carbon back to the ecological cycle through carbonization and carbon reduction. The former changes all refuses to gaseous fuel (ca. $10 \mathrm{wt} \%$ ) and inorganic carbon; the latter changes all acid/acidic gases $\left(\mathrm{SO}_{2}, \mathrm{NO}_{\mathbf{x}}, \mathrm{CO}_{2}\right)$ to inoffensive/useful substances with the inorganic carbon. Application of FCC strategy will effectively alleviate environmental pollution in a simple way. However, the essence of environment pollution is the heavy population that cannot be sustained by the earth. Therefore, no technical measure, but politics can solve the problem thoroughly.
\end{abstract}

\section{Keywords}

Environment, Pollution, Essence, Strategy, Forced Carbon Circulation (FCC)

\section{Environmental Pollution Is Due to Carbon Accumulation}

The environment would not be polluted should human being be not alive on the earth; therefore, human activity is the origin of pollution. Two things are inevitable in human activities: food and fuels in order to satisfy energy needs. Both food and fuels are composed mainly of elements carbon and hydrogen, and the products of consuming energy are $\mathrm{CO}_{2}$ and $\mathrm{H}_{2} \mathrm{O} . \mathrm{H}_{2} \mathrm{O}$ is not offensive, but the accumulated $\mathrm{CO}_{2}$ causes abnormal climate change. The author indicated [1] that the global $\mathrm{CO}_{2}$ is linearly correlated with world population for the past 160 years as shown in Figure 1 with a correlation coefficient of 0.99 . It means more people, more pollution and zero $\mathrm{CO}_{2}$ emission when the world population is less than 1.3 billion. In fact, $\mathrm{CO}_{2}$ is only part of wastes generated in human activities. Many cities/towns of China are presently surrounded by urban garbage (Figure 2). Urban 


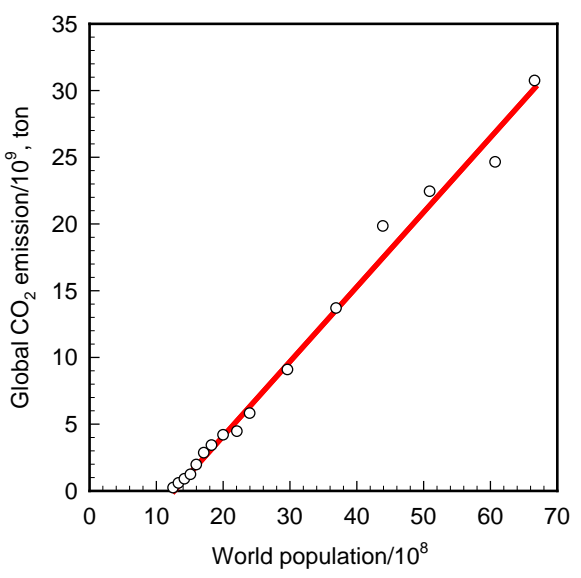

Figure 1. Correlation between global $\mathrm{CO}_{2}$ emission and world population since 1850 .

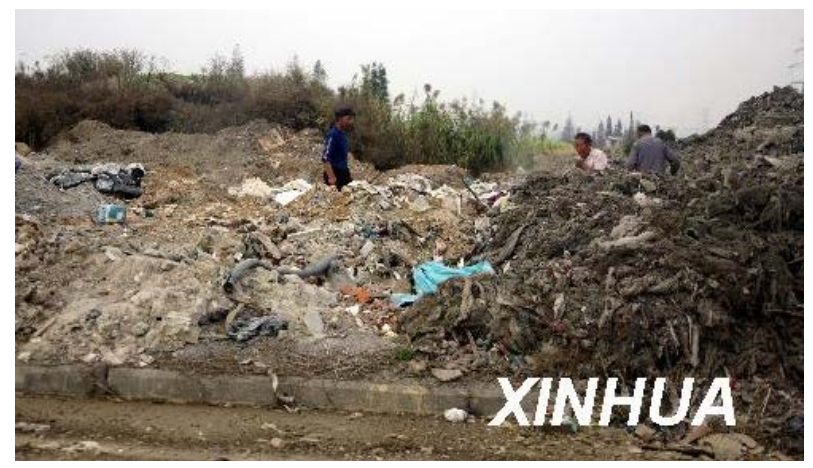

Figure 2. The landfill garbage at suburb of a city in Zhejiang Province (Taken on November 7, 2009).

garbage is only part of solid wastes of human activities, and large quantity of agricultural refuses is generated in farming and relevant activities. Aquatic weeds flourish in lakes, rivers and oceans due to pollution with nutritious wastes (Figure 3). Different kinds of solid wastes generated in human activities are also a form of carbon accumulation, and carbon left after carbonizing the wastes. Accumulation of carbon above the earth broke up the ecological balance and was reflected in environmental pollution.

\section{Forced Carbon Circulation (FCC)}

Because carbon and hydrogen are the most abundant elements in food and fuels and in the products of consuming food and fuels as well, forced carbon circulation (FCC) is proposed to bring the carbon element back to ecological cycle from refuses through carbonization and carbon reduction. Most organic and/or biomass refuses can be carbonized at relatively low temperature $\left(300^{\circ} \mathrm{C}-500^{\circ} \mathrm{C}\right)$, and poisonous gases such as dioxins do not occur at such temperature. In addition, quite many heat sources of low heat value are available in industry. Inorganic carbon and flammable gas are major products of carbonization as shown in Table $\mathbf{1}$ for an experiment with coal [2]. The inorganic carbon is used as reductant of acid/acidic oxides resulted in consuming fossil fuels. The FCC strategy is effective in treating urban garbage, agricultural refuses, aquatic weeds, and the flue gas of fuel combustion. It can also be applied to the $\mathrm{FeO} / \mathrm{Fe}_{3} \mathrm{O}_{4} / \mathrm{CO}$ cycle for the production of hydrogen [2].

\section{FCC Applied for Urban Garbage}

Urban garbage is finely classified and reutilized in developed countries; however, garbage classification seems difficult in practice for developing countries as is the situation of China, and only minor part of refuses is reutilized. Garbage incineration relies on large quantity of additional fuel, and poisonous gases such as dioxins occur 

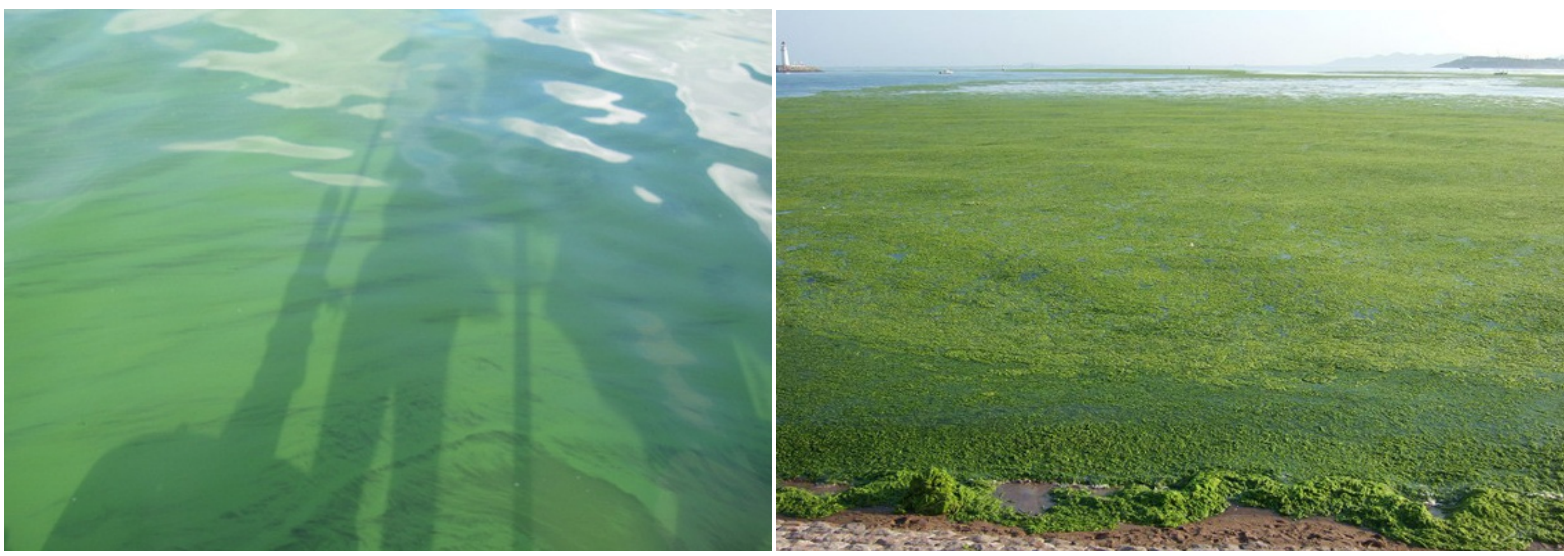

Figure 3. Aquatic weeds covered Lake Dianchi, Kunming (left) and sea water at Tsingdao (right), Shandong Province.

Table 1. Result of catalytic carbonization of coking and lean coals.

\begin{tabular}{|c|c|c|c|}
\hline \multicolumn{4}{|c|}{ Coking coal } \\
\hline Catalyst & Gas, wt\% & Combustible Fraction, \% & Tar, wt $\%$ \\
\hline $\mathrm{Ni} / \mathrm{Ce}-\mathrm{ZrO}_{2} / \gamma-\mathrm{Al}_{2} \mathrm{O}_{3}$ & 13.62 & 89.37 & 4.29 \\
\hline $9 \% \mathrm{Ni} / 10 \% \mathrm{MoO}_{3} / \gamma-\mathrm{Al}_{2} \mathrm{O}_{3}$ & 13.92 & 91.93 & 4.57 \\
\hline $\mathrm{Ni} / \mathrm{La}_{2} \mathrm{O}_{3}-\mathrm{MgO} / \gamma-\mathrm{Al}_{2} \mathrm{O}_{3}$ & 15.12 & 90.38 & 3.59 \\
\hline \multicolumn{4}{|c|}{ Lean coal } \\
\hline $\mathrm{Ni} / \gamma-\mathrm{Al}_{2} \mathrm{O}_{3}$ & 11.31 & 94.44 & 1.14 \\
\hline $\mathrm{Ni} / \mathrm{CeO}_{2} / \gamma-\mathrm{Al}_{2} \mathrm{O}_{3}$ & 8.32 & 96.32 & 2.58 \\
\hline $\mathrm{Ni} / \mathrm{La}_{2} \mathrm{O}_{3}-\mathrm{MgO} / \gamma-\mathrm{Al}_{2} \mathrm{O}_{3}$ & 8.86 & 96.58 & 2.68 \\
\hline
\end{tabular}

at the incineration temperature. Therefore, garbage incineration often encounters protest of nearby residents and most cities depend on landfills of garbage. It occupied quite large field and deteriorates the near-by environment. According to FCC strategy, garbage is classified just into two groups: that can be carbonized (CBC) and that cannot be carbonized (CNBC). The management of garbage becomes simple: carbonize $\mathrm{CBC}$ at about $300^{\circ} \mathrm{C}-$ $500^{\circ} \mathrm{C}$ and use CNBC to build up dams on sea coast or spread it over deserts. Additional fuel may not be required for carbonization since flammable gas is generated in the process of carbonization. The resulted inorganic carbon is directly applied in the reaction of carbon reduction as described in subsequent section.

\section{FCC Applied for Aquatic Weeds and Agricultural Refuses}

How to deal with aquatic weeds is a headache for Dianchi Lake, Kunming, Yunnan Province and quite many other lakes, rivers, and coastal water of China. According to FCC, the aquatic weeds provide large quantity of energy in a simple way: get the aquatic weeds out of water, and dry them up, then carbonize them at relatively low temperature and normal pressure. About $10 \mathrm{wt} \%$ flammable gas is expected to obtain in addition to inorganic carbon. The same applies to agricultural refuses. Instead of in-situ burning, farmers may sell stalks to a professional contingent. As much as $8.4 \times 10^{7}$ tons of flammable gas will be obtained in China if 1/10 of the total stalks transforms to. The obtained inorganic carbon can be used as chemical reductant or just back to cultivated land as potassium fertilizer. The carbonized agricultural stalks usually have developed porous structure with specific surface area raged in an order of magnitude 10 to $10^{2} \mathrm{~m}^{2} / \mathrm{g}$. They deserve well of cheap adsorbent for waste water treatment and once again carbonization is resorted to when saturated.

\section{FCC Applied for Hydrogen Production}

Fossil fuels will soon be exhausted and natural renewable energy cannot, as pointed out by David MacKay [3], satisfy human requirement when fossil fuels depleted. Hydrogen energy entails the hope of human future because it is theoretically renewable. The renewable hydrogen does come from water; however, cannot through 
direct decomposition. Thermo-chemical cycles allow partial decomposition of water in such a way that the oxygen valence does not change while hydrogen escapes from water molecule so that the TEG (theoretical energy gain) [4] is larger than unity. The author proposed a $\mathrm{FeO} / \mathrm{Fe}_{3} \mathrm{O}_{4} / \mathrm{CO}$ cycle where

$$
\begin{aligned}
& 3 \mathrm{FeO}+\mathrm{H}_{2} \mathrm{O}=\mathrm{H}_{2}+\mathrm{Fe}_{3} \mathrm{O}_{4} \text { at } 800^{\circ} \mathrm{C} \\
& \mathrm{Fe}_{3} \mathrm{O}_{4}+\mathrm{CO}=3 \mathrm{FeO}+\mathrm{CO}_{2} \text { at } 800^{\circ} \mathrm{C} \text { too }
\end{aligned}
$$

The yielded $\mathrm{CO}_{2}$ disappears in the reaction of carbon reduction at $900^{\circ} \mathrm{C}$ :

$$
\mathrm{CO}_{2}+\mathrm{C}=2 \mathrm{CO}
$$

All reactions proceed at ambient pressure without the aid of catalysts. The carbon generated in FCC can be here used as reductant. The net product of the cycle is $\mathrm{H}_{2}$ and CO. They are normally obtained through SMR (steam methane reforming) process at $700^{\circ} \mathrm{C}-1100^{\circ} \mathrm{C}$ from natural gas with the aid of catalysts and used for the synthesis of chemical products such as methanol, fertilizer, artificial fiber, plastics, etc.

\section{FCC Applied for Flue Gas of Coal Combustion}

Coal is a major energy source and a major pollution source either. It provides the largest share of total energy used for electricity generation, for example, $78 \%$ in China, $69 \%$ in India and 50\% in the United States. Removal of acid gases $\left(\mathrm{SO}_{2}\right.$ and $\left.\mathrm{NO}_{\mathrm{x}}\right)$ from the flue gas of coal combustion doubled the cost of power generation, and the capture of $\mathrm{CO}_{2}$ costs at least equivalent to double the market price of power coal [5]. The extremely high cost means abandon of capture. Zero emission is possible if FCC applies to the coal-combustion flue gas. In addition to minor content of $\mathrm{SO}_{2}$ and $\mathrm{NO}_{\mathrm{x}}$, the major products of coal combustion are $\mathrm{CO}_{2}$ and $\mathrm{H}_{2} \mathrm{O}$. All of them can be reduced by carbon to useful or inoffensive substances:

$$
\begin{gathered}
\mathrm{CO}_{2}+\mathrm{C}=2 \mathrm{CO}+172.46 \mathrm{~kJ} \cdot \mathrm{mol}^{-1} \\
\mathrm{H}_{2} \mathrm{O}+\mathrm{C}=\mathrm{CO}+\mathrm{H}_{2}+131.29 \mathrm{~kJ} \cdot \mathrm{mol}^{-1} \\
\mathrm{SO}_{2}+2 \mathrm{CO}=2 \mathrm{CO}_{2}+\mathrm{S}-269.13 \mathrm{~kJ} \cdot \mathrm{mol}^{-1} \\
\mathrm{NO}_{2}+\mathrm{CO}=\mathrm{NO}+\mathrm{CO}_{2}-225.91 \mathrm{~kJ} \cdot \mathrm{mol}^{-1} \\
2 \mathrm{NO}+2 \mathrm{CO}=\mathrm{N}_{2}+2 \mathrm{CO}_{2}-746.46 \mathrm{~kJ} \cdot \mathrm{mol}^{-1}
\end{gathered}
$$

Reactions (4) and (5) are endothermic, and their conversion can be calculated based on fundamental thermodynamic data as that listed in Table 2 [6]. The calculated theoretical conversion of the two reactions is shown in Figure 4 as a function of temperature. Complete conversion is expected at $900^{\circ} \mathrm{C}$. Reactions (6)-(8) with minus thermal effects are exothermic and complete conversion is theoretically assumed at ambient temperature whenever reactions initiated. The carbon monoxide here generated can be sent to the $\mathrm{FeO} / \mathrm{Fe}_{3} \mathrm{O}_{4}$ oxidation/reduction cycle for the production of hydrogen as above mentioned, and the carbon here used can be provided by carbonization of solid garbage/aquatic weeds or agricultural refuses.

\section{Discussion and Conclusion}

Technical strategy and/or methods known to us are essentially useless for the elimination of carbon emission and the abnormal climate change it caused. The CCS strategy is not practical because the capture cost is too high to be applied in practice and it can only capture the centralized emission. However, the centralized emission accounts for only $1 / 4$ to $1 / 3$ of the total. Electricity driven vehicles are something like that said by a proverb: plug one's ears while stealing a bell because the electricity is most likely produced in burning coal so that the global carbon emission unchanged while some places are locally cleaned. Natural energy cannot satisfy the energy needs presently and even for the future. Compared to them, the FCC strategy is practical and efficient to alleviate environmental pressure.

However, as the linear relationship between global $\mathrm{CO}_{2}$ emission and world population revealed that the essence of environment problem is the problem of population. People must realize the crisis, the living crisis, is stepping closer and closer if considering environmental problem in connection with the depletion schedule of natural resources. Think about the situation 65 years later. The world population will be doubled (more or less 
Table 2. Thermodynamic data required for conversion calculation of Reactions (1) and (2).

\begin{tabular}{|c|c|c|c|c|c|}
\hline $25^{\circ} \mathrm{C}$ & $\mathrm{C}(\mathrm{s})$ & $\mathrm{CO}_{2}(\mathrm{~g})$ & $\mathrm{CO}(\mathrm{g})$ & $\mathrm{H}_{2} \mathrm{O}(\mathrm{g})$ & $\mathrm{H}_{2 \mathrm{v}}(\mathrm{g})$ \\
\hline$\Delta_{f} H_{m}^{\theta} / \mathrm{kJ} \times \mathrm{mol}^{-1}$ & 0 & -393.51 & -110.53 & -241.826 & 0 \\
\hline$\Delta_{f} H_{m}^{\theta} / \mathrm{kJ} \times \mathrm{mol}^{-1}$ & 0 & -394.36 & -137.17 & -228.6 & 0 \\
\hline$T, K$ & \multicolumn{5}{|c|}{$C_{p, m} / J \cdot K \cdot \mathrm{mol}^{-1}$} \\
\hline 298.15 & 8.536 & 29.141 & 37.135 & 33.598 & 28.836 \\
\hline 300 & 8.61 & 29.142 & 37.22 & 33.606 & 28.849 \\
\hline 400 & 11.974 & 29.34 & 41.328 & 34.283 & 29.181 \\
\hline 500 & 14.537 & 29.792 & 44.627 & 35.259 & 29.26 \\
\hline 600 & 16.607 & 30.44 & 47.327 & 36.371 & 29.327 \\
\hline 700 & 18.306 & 31.17 & 49.569 & 37.557 & 29.44 \\
\hline 800 & 19.699 & 31.898 & 51.442 & 38.8 & 29.623 \\
\hline 900 & 20.832 & 32.573 & 53.008 & 40.084 & 29.88 \\
\hline 1000 & 21.739 & 33.178 & 54.32 & 41.385 & 30.204 \\
\hline 1100 & 22.452 & 33.709 & 55.423 & 42.675 & 30.58 \\
\hline 1200 & 23 & 34.169 & 56.354 & 43.932 & 30.991 \\
\hline 1300 & 23.409 & 34.568 & 57.144 & 45.138 & 31.422 \\
\hline 1400 & 23.707 & 34.914 & 57.818 & 46.281 & 31.86 \\
\hline 1500 & 23.919 & 35.213 & 58.397 & 47.356 & 32.296 \\
\hline
\end{tabular}

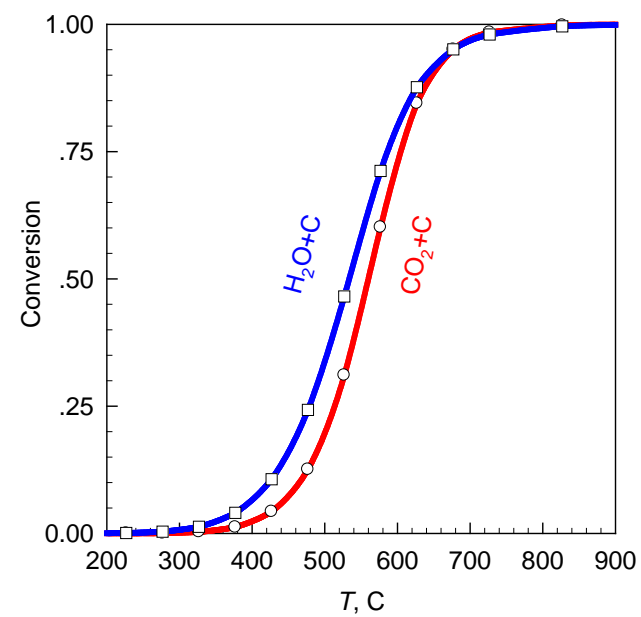

Figure 4. Theoretical conversion of major reduction reactions at different temperature..

around 14 billion) if the present growth rate (1.14\%) is keeping on, and the global emission of $\mathrm{CO}_{2}$ is almost doubled either. Oil and natural gas have been run out, and the other natural resources are also either empty or closing depletion. Fresh water may be in very short since glaciers may have been disappeared and rivers lost headstreams and draught. Food may also be in very short because most farm land might have been severely polluted. Competition and fighting for the last living resources to survive would be severer year by year. The earth likes just a ferryboat. It would sink when the ferryboat passengers are overloaded. People can imagine what would happen on the boat when it is sinking. The most important for us to do is not the development of economy following conventional model, but to survive human civilization gently, i.e., switching the growth rate of world population to negative immediately. The curve of world population growth rate (Figure 5) [7] shows a downward peak at the end of 50's and early 60's last century, which is largely due to the ridiculous "Three Red Banners" policy that led to a great famine in China and quite many people died in hungry [8]. A re- 


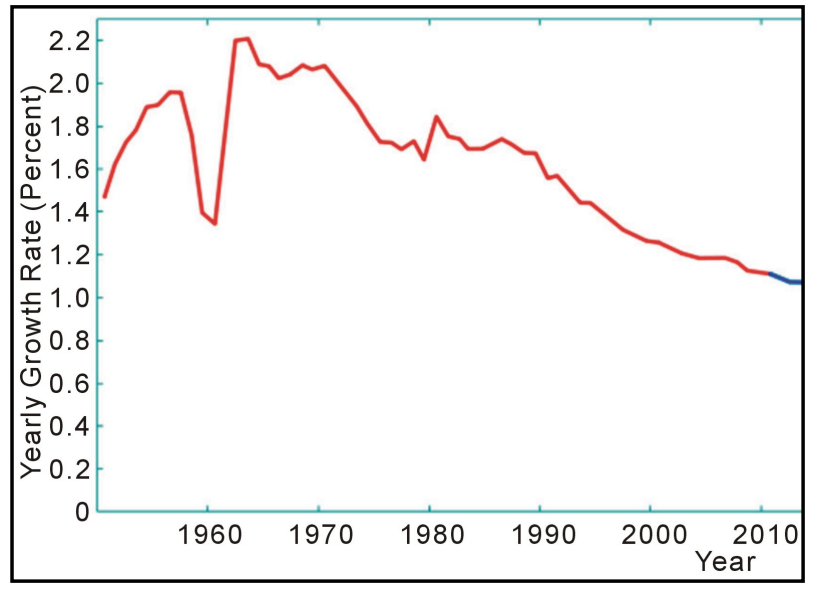

Figure 5. World population growth rate since 1950 (red).

markable yet gentle decrease is shown for 1970's due largely to the "One Child Policy" of China issued in 1975. Of course nobody wants Mao's policy returned, but the world's attention must switch from "carbon emission” to "breeding control". The personal right and freedom to breed must subordinate the world No. 1 target of surviving human civilization. Lao Tzu told people "following nature (Dao Fa Zi Ran)". It means human activities must be compatible with natural limitation. Any theory or policies are not valid or harmful if it does not consider the compatibility of its consequence with nature.

\section{References}

[1] Zhou, L. (2012) Carbon Emission: Invalid Strategy and Ecological Rule. Low Carbon Economy, 3A, 80-82. http://dx.doi.org/10.4236/lce.2012.323011

[2] Zhou, Y.P., Sun, Y., Su, W. and Zhou, L. (2013) Experimental Studies on $\mathrm{FeO} / \mathrm{Fe}_{3} \mathrm{O}_{4}$ Cycle Complemented with Carbon Gasification for Producing Hydrogen. Energy \& Fuels, 27, 4071-4076. http://dx.doi.org/10.1021/ef4004939

[3] MacKay, D.J.C. (2009) Sustainable Energy, without the Hot Air. UIT Cambridge Ltd., Cambridge.

[4] Zhou, Y.P., Jia, C.X., Zhang, Y., Liu, C.F., Huang, D.S., Sun, Y. and Zhou, L. (2008) Experimental Study on a New Process of Producing Hydrogen in Consumption of Water and Coal. AIChE Journal, 54, 1388-1395. http://dx.doi.org/10.1002/aic.11478

[5] Ian Murray \& Company Ltd. (2008) REPORT: Alberta $\mathrm{CO}_{2}$ Capture Cost Survey and Supply Curve.

[6] Lide, D.R. (2006-2007) CRC Handbook of Chemistry and Physics. 87th Edition, Part 5.

[7] Wikipedia (2013) World Population. http://en.wikipedia.org/wiki/World population

[8] Yang, J.S. (2007) Grave Monuments. Tian Di (Cosmos Books) Press, Hong Kong. (in Chinese) 